\title{
Effects of Soil Quality Enhancement on Pollinator-Plant Interactions
}

\author{
Yasmin J. Cardoza, ${ }^{1}$ Gabriel K. Harris, ${ }^{2}$ and Christina M. Grozinger ${ }^{3}$ \\ ${ }^{1}$ Department of Entomology, North Carolina State University, Raleigh, NC 27695-7613, USA \\ ${ }^{2}$ Department of Food, Bioprocessing and Nutrition Sciences, North Carolina State University, Raleigh, NC 27695-7624, USA \\ ${ }^{3}$ Department of Entomology, Center for Pollinator Research, The Pennsylvania State University, University Park, PA 16802, USA \\ Correspondence should be addressed to Yasmin J. Cardoza, yasmin_cardoza@ncsu.edu
}

Received 4 June 2012; Accepted 8 August 2012

Academic Editor: Tugrul Giray

Copyright ( $) 2012$ Yasmin J. Cardoza et al. This is an open access article distributed under the Creative Commons Attribution License, which permits unrestricted use, distribution, and reproduction in any medium, provided the original work is properly cited.

\begin{abstract}
Both biotic and abiotic factors can affect soil quality, which can significantly impact plant growth, productivity, and resistance to pests. However, the effects of soil quality on the interactions of plants with beneficial arthropods, such as pollinators, have not been extensively examined. We studied the effects of vermicompost (earthworm compost, VC) soil amendment on behavioral and physiological responses of pollinators to flowers and floral resources, using cucumbers, Cucumis sativus, as our model system. Results from experiments conducted over three field seasons demonstrated that, in at least two out of three years, VC amendment significantly increased visit length, while reducing the time to first discovery. Bumblebee (Bombus impatiens) workers that fed on flowers from VC-amended plants had significantly larger and more active ovaries, a measure of nutritional quality. Pollen fractions of flowers from VC-grown plants had higher protein compared to those of plants grown in chemically fertilized potting soil. Nectar sugar content also tended to be higher in flowers from VC-grown plants, but differences were not statistically significant. In conclusion, soil quality enhancement, as achieved with $\mathrm{VC}$ amendment in this study, can significantly affect plant-pollinator interactions and directly influences pollinator nutrition and overall performance.
\end{abstract}

\section{Introduction}

Mutualisms between flowering plants and animal pollinators are an integral ecological relationship of vital importance for both natural and agricultural ecosystems [1]. Approximately $87.5 \%$ of flowering plants use animal-mediated pollination to set seed and fruit [2], corresponding to $70 \%$ of our agricultural crops [3]. Therefore, in order to insure the security of our pollinator-dependent crop species, it is imperative to characterize the mechanisms and practices that can enhance pollinator ecosystem services in managed landscapes. However, populations of honey bees, bumble bees, and other native pollinators have been in decline worldwide [4-7]. A reduction in floral resources (quantity and quality) used by pollinators is hypothesized to be a major reason behind this pollinator loss $[5,7,8]$. Thus, there has been increasing interest in understanding how landscape ecology, and, in particular, nutrition provided by flowering plants, can affect and potentially improve pollinator populations in natural and managed ecosystems [9, 10]. Improving nutritional resources for pollinators in agricultural landscapes can be especially important, given that one third of land area worldwide is currently under agriculture management [11] and another billion hectares will likely be converted to agriculture by 2050 as crop production expands to feed a growing human population.

While most studies of plant-pollinator interactions have focused simply on how the plant community can affect pollinator abundance and diversity, the quality of the soil can significantly influence plant-pollinator interactions. Soil quality can influence the production of flowers $[12,13]$, pollen [14], and nectar [15-17] and can lead to changes in pollinator visitation patterns $[12,13]$. However, these previous studies have focused almost exclusively on the impact of the addition of chemical fertilizers to the soil in natural ecosystems, and the outcomes have been variable. 
In previous studies, we have demonstrated that vermicompost (VC; earthworm-produced compost) amendment to the soil significantly improves plant resistance to herbivorous caterpillar and aphid species in brassicaceous plant species [18-20]. Here, we sought to extend these investigations to characterize the effects of $\mathrm{VC}$ amendment on plant-pollinator interactions. First, we evaluated the effects of VC on cucumber, Cucumis sativus L., flower traits over three years. Next, we examined the effects of VC amendment on behavioral responses of pollinators to these plants in the field over three field seasons. We also examined differences between plants grown in VC-treated versus chemically fertilized soils, in the final year of the study, to determine if VC effects were simply due to differences in nutrient availability. Finally, we determined if VC amendment improved the nutritional quality of floral resources, by examining the physiological characteristics of bumblebee (Bombus impatiens) workers fed flowers from VC amended versus CF (chemically-fertilized) plants, and by quantifying sugar and protein content in the nectar and pollen of these flowers.

\section{Methods}

2.1. Plants. Cucumber plants, Cucumis sativus, "Boston Pickler" were grown in Sun-Gro Redi-Earth commercial potting mix (CF), or this soil mix amended with $1 / 3 \mathrm{v}: \mathrm{v}$ vermicompost from Oregon Soil Corporation (Oregon City, OR, $\mathrm{VC}$ ). This level of VC amendment was chosen on the basis of published results [21], as well as plant-insect interactions studies conducted previously [18-20]. Only CF and VC treatments were compared in the 2008 and 2009 field seasons. However, in 2010, we also sought to determine if the differential pollinator attraction to VC-grown flowers documented in 2008 and 2009 was simply due to enhanced levels of major plant nutrients $(\mathrm{N}, \mathrm{P}, \mathrm{K})$ in VC-amended soil, or if other factors (microbial or chemical) are involved. Thus, in 2010 we also included plants grown in unfertilized potting soil $(\mathrm{NF})$, and plants grown in soil supplemented with a slow release fertilizer (30-3-10 N-P-K; Regal Chemical Company, 600 Branch Dr, Alpharetta, Georgia) with nutrient levels equivalent to those of VC (VCEQ). Levels of these nutrients in VC were determined in a previously published study [20].

Seeds were sown in pairs in 15-centimeter diameter terracotta pots, and seedlings were thinned down to one per pot when they reached the 2 nd true-leaf stage. Plants were grown in a greenhouse under natural summer-lighting conditions and $28 \pm 5^{\circ} \mathrm{C}$ and $60-70 \% \mathrm{RH}$. All plants were watered 3 times per week with 100-200 $\mathrm{mL}$ each.

2.2. Plant Traits. Cucumber plants were used for experiments one week after the onset of flowering (30-35 d after planting). Time to flowering was also noted for each of the treatments. Since pollinator attraction may be influenced by visual factors, such as flower display size [22], the number of flowers and flower weights were obtained at the end of each assay. Additionally, in 2009, we measured corolla diameter and calyx length for sets of ten randomly selected flowers from each of six different CF and VC plants. The measurements for ten flowers were pooled to obtain average calyx and corolla sizes on a per plant basis.

2.3. Pollinator Responses. In 2008 and 2009, assays were run as 2-way choice test between one plant each of $\mathrm{CF}$ and VC treatments. In 2010, assays were run as a 4-way choice with all four treatments (NF, CF, VCEQ, VC). In all field seasons, plants were placed in a single row approximately $1 \mathrm{~m}$ away from one another. The location of each treatment was rotated for each assay to control for any positional effects. The experiments were carried out at the NCSU campus in an open field, approximately $20 \times 20 \mathrm{~m}$, surrounded by native vegetation. Pollinator response was observed during two $15 \mathrm{~min}$ intervals, with a 10 minute recess in between. The pollinator number, type (bumblebee, honey bee, or nonbumblebee native bee) and visit length $(\mathrm{min})$ was recorded for each of the treatments. Assays were conducted singly or in duplicates, only on nonovercast days and always between $10 \mathrm{AM}$ and $12 \mathrm{PM}$. All replicates were obtained between late June and mid August, for a total of 11 replicates in 2008, 14 replicates in 2009, and 8 replicates in 2010 .

2.4. Laboratory B. impatiens Microcolony Feeding Experiments. Queenright research colonies of B. impatiens L. were obtained from Koppert Biological Systems Inc-USA (Romulus, MI) and were maintained in a room kept at $26 \pm 2{ }^{\circ} \mathrm{C}$, approximately $60 \% \mathrm{RH}$ and a $14: 10 \mathrm{~L}: \mathrm{D}$ cycle. Colonies were provided with ad-libitum 50\% sugar syrup and pollen: honey dough. Fresh food was provided every other day.

Since the field trials showed consistent and significant differences between CF and VC treatments, we compared only these two treatments in this and all subsequent experiments. Given that queenless worker bumblebees can activate their ovaries and initiate egg laying [23-25], and higher levels of dietary protein shorten the time-to-initiate egg-laying and increase egg-laying rates in queenless Bombus terrestris workers $[26,27]$, we examined the effects of feeding queenless bumblebees flowers from $\mathrm{CF}$ and VC plants.However, in order to reduce the time required for the experiment and have a detailed measurement of individual bee physiology, we measured ovary activation, rather than egg laying, in three worker bees maintained in queenless micro colonies (see below for details).

All plants were used one week after the onset of flowering. Worker bees were randomly collected from 5 different queenright bumblebee colonies. Insects were weighed individually and sets of three bees of approximately the same weight were placed in $10 \times 10 \times 7 \mathrm{~cm}$ Plexiglas cages (see Figure 1). Each cage was provided with 2 liquid feeders containing 25\% sugar syrup. The feeders were made by cutting the bottoms of $1.5 \mathrm{~mL}$ plastic micro centrifuge tubes and plugging the openings with rolled up cotton pieces to help wick out the syrup. Syrup in the feeders was replaced every other day. Each cage was also provided with six flowers from CF or VC plants. Fresh flowers were collected daily and their petioles were inserted in $2 \%$ agar blocks to keep their turgidity during their time inside the bee cages. Cages were kept for $7 \mathrm{~d}$ under 


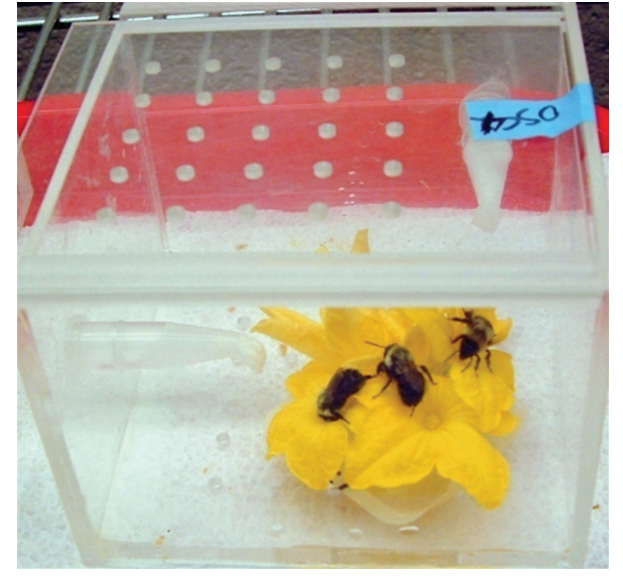

Figure 1: Example of queenless microcolony used to compare effects of VC-grown versus unamended (CF) flowers on B. impatiens reproductive physiology.

the same environmental conditions described for the bee colonies above. At the end of the seven days, all bees were killed by freezing. Bees in each cage were collectively weighed and then dissected. A total of 9 replicates were obtained in three trials (different dates) of two, three, and four replicates/treatment each. Data were collected on weight difference (initial-final weights), number of bees showing ovary activation (i.e., ovaries $>3 \mathrm{~mm}$ long and oocyte development), ovary length, number of oocytes and oocyte length (mean for the four most proximal to the ovipositor).

2.5. Nectar and Pollen Analyses. We used male flowers for sample collection because of their abundance during early flowering, because they were the most predominant during our field assays, and to avoid potential chemical differences due to flower gender. Nectar was collected from individual flowers using $20 \mu \mathrm{L}$ glass micropipettes to suction all liquid from inside the flower cup. Pollen was collected by manually excising whole anthers from each flower. All flowers were collected between $10 \mathrm{am}$ and noon, and nectar and pollen were obtained immediately following abscission. For each sample, batches of 20 flowers were collected from 2-3 plants in one day. Twelve samples were collected from CF and VC flowers over the course of several days. Corolla diameter and weights of nectar and pollen fractions were recorded at the time of collection. All samples were collected on ice and stored frozen at $-80^{\circ} \mathrm{C}$ until needed for chemical analyses.

Flowers from Cucumis spp. have been reported to contain glucose, fructose, and sucrose [28]. Nectar samples were analyzed for these three sugars by high pressure liquid Chromatography (HPLC, Rheodyne/IDEX, Oak Harbor, WA). Nectar samples were diluted using deionized water and passed through a $0.45 \mathrm{um}$ syringe filter. Sugar fraction separation was carried out by on an HPX- $87 \mathrm{H} 30 \mathrm{~cm}$ column from BioRad (Hercules, CA) with mobile phase: $0.03 \mathrm{~N}$ sulfuric acid. The analytical system was composed of a Thermo Separation Products Refractive Index detector coupled with a P1000 pump set at a flow rate of $0.9 \mathrm{~mL} / \mathrm{min}$ and
Chromquest data analysis software. A four-point calibration curve was obtained with external standards made with high purity, glucose, and fructose to facilitate sugar quantification within each sample.

Pollen samples were thawed and oven dried for 30 minutes to remove excess moisture. To analyze pollen constituents, dried, thawed anthers were extracted by sonication for 50 minutes in $\mathrm{pH} 70.1 \mathrm{M}$ potassium phosphate buffer adjusted to $\mathrm{pH} 7$ with $0.1 \mathrm{M} \mathrm{NaOH}$ for protein determination. Approximately $20 \mathrm{mg}$ (weighed to the nearest $\mathrm{mg}$ ) of dried anthers were extracted in $1 \mathrm{~mL}$ of buffer. Samples were then transferred to $1.5 \mathrm{~mL}$ microcentrifuge tubes and centrifuged at maximum speed for $10 \mathrm{~min}$ to remove particulates. The supernatant was transferred to standard $(18 \times$ $150 \mathrm{~mm}$ ) borosilicate test tubes for dilution to appropriate concentrations for analysis. In order to read the BCA accurately, extracts were further diluted 1:60 with buffer prior to addition of the BCA reagent. Diluted pollen extracts were analyzed for total protein using the standard BCA method (Fisher Scientific, Pittsburg, PA). Extract aliquots of $0.1 \mathrm{~mL}$ were added to individual test tubes followed by the addition of $2 \mathrm{~mL}$ of BCA working reagent. The tubes were incubated in the dark at $37^{\circ} \mathrm{C}$ for 30 minutes, samples were then transferred to cuvettes for UV/Vis spectrophotometric (Spectronic Genesys 2, Fisher Scientific, Pittsburg, PA) measurement at $562 \mathrm{~nm}$.

2.6. Statistical Analyses. Because preliminary statistical analysis revealed a significant effect of year, we analyzed and present the results of the different years separately. Therefore, for each of the three years, treatment effects on pollinator response variables such as discovery time (time to first visitor), number of pollinator visits, pollinator type (bumblebee, honey bee, non-bumblebee native bee) and visit length were evaluated with ANOVAs followed by Tukey's mean separation tests. The effect of soil treatment on pollinator visitor type number was evaluated using a Poisson distribution analyses (Proc GLIMMIX) [29], since we would expect each type to be randomly distributed among the treatments. Data for pollinator type number were $\ln (x+1)$ transformed to comply with the assumptions of normality, but values for means and standard errors in tables are for the untransformed values. Analyses of variance were also used to determine the effects of trial, treatment (CF and VC flowers), and their interaction on the weight difference, survival, ovary length, number of oocytes, and oocyte length in the microcolony feeding experiments. Tukey's mean separation tests were also performed for significant ANOVAs. Differences in flower size between CF and VC plants were evaluated using $t$-tests (PROC $t$-test) [29]. The effect of soil treatment on flower weight corolla diameter, pollen and nectar fraction weight, and sugar and protein content were also evaluated using $t$-tests.

\section{Results}

3.1. 2008 Field Experiment. Data for flower traits and pollinator responses are provided for each year on Tables 1 and 2 , respectively. In 2008, number of flowers per plant did not 
TABLE 1: Effect of soil treatment on cucumber flower traits in field assays. Two-way choice in 2008 and 2009 included CF (potting soil plus Osmocote 14-14-14 at the label rate) and VC (potting soil plus 33\% vermicompost) treatments. Four way choice field assays in 2010 included CF, VC, NF (potting soil without fertilizer), and VCEQ (potting soil plus slow release fertilizer with equivalent NPK as those provided by vermicompost) treatments. Values present means \pm SE from 11, 14, and 8 replicates for each season, respectively. Means within rows followed by the same superscript letter are not significantly different (Tukey's mean separation test, $P>0.05$ ).

\begin{tabular}{|c|c|c|c|c|c|}
\hline Year & Response variable & $\mathrm{CF}$ & $\mathrm{VC}$ & $\mathrm{NF}$ & VCEQ \\
\hline \multirow{3}{*}{2008} & Number flowers & $9.6 \pm 0.87^{\mathrm{a}}$ & $9.0 \pm 0.41^{\mathrm{a}}$ & NA & NA \\
\hline & Flowering time (d) & $30 \pm 0.50^{\mathrm{a}}$ & $27.8 \pm 0.52^{\mathrm{b}}$ & NA & NA \\
\hline & Flower weight (g) & $0.2 \pm 0.01^{\mathrm{a}}$ & $0.23 \pm 0.00^{\mathrm{b}}$ & NA & NA \\
\hline \multirow{3}{*}{2009} & Number flowers & $12.8 \pm 1.44^{\mathrm{a}}$ & $12.8 \pm 1.28^{\mathrm{a}}$ & NA & NA \\
\hline & Flowering time $(\mathrm{d})$ & $30.7 \pm 0.22^{\mathrm{a}}$ & $29.4 \pm 0.17^{\mathrm{b}}$ & NA & NA \\
\hline & Flower weight (g) & $0.23 \pm 0.01^{\mathrm{a}}$ & $0.25 \pm 0.01^{\mathrm{b}}$ & NA & NA \\
\hline \multirow{3}{*}{2010} & Number flowers & $9.8 \pm 0.1 .36^{\mathrm{b}}$ & $6.3 \pm 0.41^{\mathrm{a}}$ & $4.6 \pm 0.29^{\mathrm{a}}$ & $5.1 \pm 0.33^{\mathrm{a}}$ \\
\hline & Flower time $(\mathrm{d})$ & NA & NA & NA & NA \\
\hline & Flower weight (g) & $0.25 \pm 0.01^{\mathrm{b}}$ & $0.32 \pm 0.01^{\mathrm{c}}$ & $0.23 \pm 0.01^{\mathrm{ab}}$ & $0.20 \pm 0.01^{\mathrm{a}}$ \\
\hline
\end{tabular}

TABLE 2: Effect of soil treatment on pollinator responses to cucumber plants in field assays. Two-way choice in 2008 and 2009 included CF (potting soil plus Osmocote 14-14-14 at the label rate) and VC (potting soil plus 33\% vermicompost) treatments. Four way choice field assays in 2010 included CF, VC, NF (potting soil without fertilizer), and VCEQ (potting soil plus slow release fertilizer with equivalent NPK as those provided by vermicompost) treatments. Values represent means \pm SE from 11, 14 and 8 replicates for each season respectively. Means within rows followed by the same superscript letter are not significantly different (Tukey's mean separation test, $P>0.05$ ).

\begin{tabular}{|c|c|c|c|c|c|}
\hline Year & Response variables & $\mathrm{CF}$ & $\mathrm{VC}$ & NF & VCEQ \\
\hline \multirow{6}{*}{2008} & Discovery time & $10.3 \pm 2.68^{\mathrm{a}}$ & $7.7 \pm 1.86^{\mathrm{a}}$ & NA & NA \\
\hline & Number Visits & $8.3 \pm 1.68^{\mathrm{a}}$ & $9.1 \pm 0.86^{\mathrm{a}}$ & NA & NA \\
\hline & Visit length (min) & $1.1 \pm 0.32^{\mathrm{a}}$ & $1.9 \pm 0.29^{\mathrm{b}}$ & NA & NA \\
\hline & Bumblebee (\%) & $66.4 \pm 8.25^{\mathrm{a}}$ & $65.4 \pm 8.67^{\mathrm{a}}$ & NA & NA \\
\hline & Honey bees (\%) & $11.7 \pm 5.79^{\mathrm{a}}$ & $8.0 \pm 4.5^{\mathrm{a}}$ & NA & NA \\
\hline & Other native bees (\%) & $21.8 \pm 9.53^{\mathrm{a}}$ & $26.4 \pm 9.26^{\mathrm{a}}$ & NA & NA \\
\hline \multirow{6}{*}{2009} & Discovery time & $7.7 \pm 1.84^{\mathrm{a}}$ & $3.92 \pm 1.05^{\mathrm{b}}$ & NA & NA \\
\hline & Number Visits & $13.4 \pm 1.72^{\mathrm{a}}$ & $15.6 \pm 1.88^{\mathrm{a}}$ & NA & NA \\
\hline & Visit length (min) & $1.3 \pm 0.14^{\mathrm{a}}$ & $2.1 \pm 0.24^{\mathrm{b}}$ & NA & NA \\
\hline & Bumblebee (\%) & $94.3 \pm 32.82^{\mathrm{a}}$ & $81.0 \pm 27.17^{\mathrm{a}}$ & NA & NA \\
\hline & Honey bees (\%) & $0 \pm 0.0^{\mathrm{a}}$ & $0 \pm 0.0^{\mathrm{a}}$ & NA & NA \\
\hline & Other native bees $(\%)$ & $5.6 \pm 1.76^{\mathrm{a}}$ & $18.9 \pm 3.38^{\mathrm{b}}$ & NA & NA \\
\hline \multirow{6}{*}{2010} & Discovery (min) & $20.5 \pm 3.96^{\mathrm{b}}$ & $13.9 \pm 3.81^{\mathrm{c}}$ & $43.4 \pm 1.62^{\mathrm{a}}$ & $19.6 \pm 3.61^{b}$ \\
\hline & Number Visits & $3.6 \pm 1.26^{\mathrm{a}}$ & $7.0 \pm 2.22^{\mathrm{a}}$ & $3.1 \pm 1.20^{\mathrm{a}}$ & $3.0 \pm 1.41^{\mathrm{a}}$ \\
\hline & Visit length (min) & $0.18 \pm 0.07^{\mathrm{b}}$ & $0.67 \pm 0.23^{c}$ & $0.05 \pm 0.08^{\mathrm{a}}$ & $0.20 \pm 0.08^{\mathrm{b}}$ \\
\hline & Bumblebee (\%) & $43.3 \pm 16.75^{\mathrm{a}}$ & $24.2 \pm 11.66^{\mathrm{a}}$ & $22.8 \pm 9.72^{\mathrm{a}}$ & $48.9 \pm 18.52^{\mathrm{a}}$ \\
\hline & Honey bees (\%) & $19.2 \pm 12.31^{\mathrm{a}}$ & $26.1 \pm 9.99^{\mathrm{a}}$ & $26.9 \pm 12.71^{\mathrm{a}}$ & $13.5 \pm 12.39^{\mathrm{a}}$ \\
\hline & Other native bees $(\%)$ & $12.5 \pm 12.50^{\mathrm{a}}$ & $49.6 \pm 15.70^{\mathrm{b}}$ & $12.8 \pm 8.31^{\mathrm{a}}$ & $12.5 \pm 12.50^{\mathrm{a}}$ \\
\hline
\end{tabular}

differ between treatments, but VC plants flowered significantly earlier $(F=3.81$; df $=1,29 ; P=0.033)$, (Table 1 ) and had significantly heavier flowers $(F=49.94$; $\mathrm{df}=1,29$; $P<0.0001$ ), (Table 1).

Time to first discovery, although shorter for the VC plants, was not statistically different (Table 2). However, the pollinators spent significantly more time on the VC flowers $(F=6.86 ; \mathrm{df}=1,29 ; P=0.0035)$, (Table 2$)$. The number of visits and pollinator type was comparable between the treatments though there was a tendency for more visits to $\mathrm{VC}$ plants (Table 2). Pollinator types were bumblebees, honey bees and nonbumblebee native (Megachillidae with an occasional visit by Peponapis squash bees, Xylocopa carpenter bees, Hesperidae butterflies, and Syrphidae flies).

3.2. 2009 Field Experiment. We again compared VC and CF plants in these experiments. Flower corolla diameter and calyx length did not differ significantly between CF and VC plants. Corolla diameter mean $\pm \mathrm{SE}$ in $\mathrm{cm}$ was $4.6 \pm 0.19$ for $\mathrm{VC}$ and $4.5 \pm 0.16$ for CF plants. Calyx length mean $\pm \mathrm{SE}$ in $\mathrm{cm}$ was $0.69 \pm 0.007$ for VC and $0.69 \pm 0.012$ for CF plants. Similar to 2008, the number of flowers was not significantly 


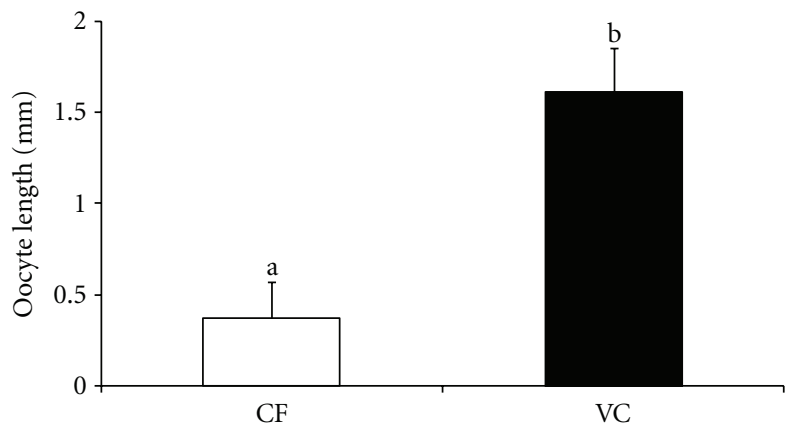

(A)

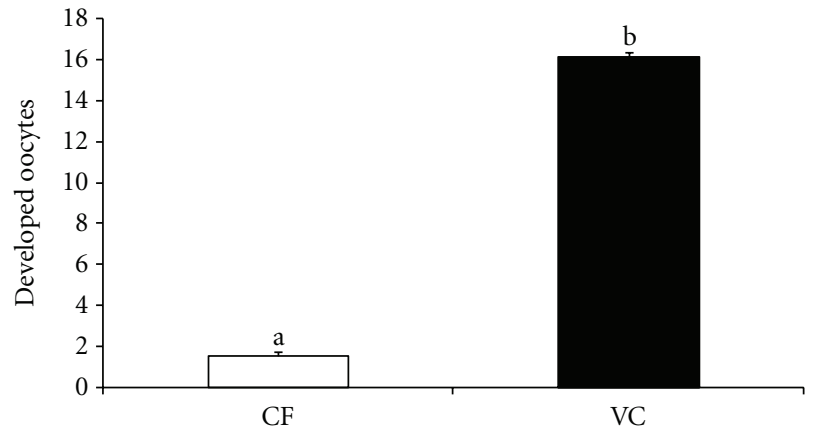

(B)

FIGURE 2: Effect of feeding on flowers from cucumber plants grown in unamended (CF) soil and VC-amended soil on (A) Oocyte length and (B) Developed oocyte number. Values represent means for 9 replicates and error bars are equivalent to 1SE. Bars headed by the same letter are not significantly different, Tukey's mean separation test $(P>0.05)$.

TABle 3: Bombus impatiens survival, weight, and ovary length of bees in queenless micro-colonies fed flowers from plants grown on CF or VC-amended soil. Values represent means \pm SE for 9 replicates. Means within rows followed by the same superscript letter are not significantly different (Tukey's mean separation test, $P>0.05$ ).

\begin{tabular}{lcr}
\hline Response variable & CF & VC \\
\hline Survival $(\%)$ & $81.6 \pm 7.99^{\mathrm{a}}$ & $96.3 \pm 6.33^{\mathrm{a}}$ \\
Weight $(\mathrm{mg})$ & $371 \pm 19.8^{\mathrm{a}}$ & $426 \pm 25.0^{\mathrm{a}}$ \\
Ovary length $(\mathrm{mm})$ & $3.4 \pm 0.77^{\mathrm{a}}$ & $5.0 \pm 0.41^{\mathrm{b}}$ \\
\hline
\end{tabular}

different (Table 1); time to first flowering was again shorter in VC plants compared to CF plants, but this was marginally significant $(F=3.92 ; \mathrm{df}=1,46 ; P=0.050)$, (Table 1$)$; and flower weights were also larger for VC plants $(F=6.72$; df $=1,26 ; P=0.0390)$, (Table 1$)$.

Time to first discovery was significantly different between treatments, with pollinators finding VC plants faster than $\mathrm{CF}$ plants $(F=4.42$; df $=1,50 ; P=0.0454)$ (Table 2$)$. There was also a significant effect on pollinator visit length $(F=6.24$; $\mathrm{df}=1,50 ; P=0.0345)$, with insects spending more time on VC versus CF flowers (Table 2). Number of pollinator visits was not significantly different between treatments, though tended to be higher for VC compared to CF plants (Table 2). Similar to 2008, bumblebees were the predominant pollinators in both treatments (Table 2), but this was not significantly different between treatments, while honey bee visits were negligible (Table 2 ). There were, however, a significantly higher proportion of non-bumblebee pollinator visitors to $\mathrm{VC}$ versus $\mathrm{CF}$ flowers $(F=17.76 ; P=0.0006)$, (Table 2).

3.3. 2010 Field Experiment: Soil Nutrient Effects on Plant and Pollinator Responses. The number of flowers was significantly different among the treatments with NF plants having higher numbers compared to all other treatments $(F=9.59$; df $=3,28 ; P<0.0001$ ), (Table 1). Time to first flowering was not recorded in this season. Flower weight was highest for the VC, followed by CF and NF treatments and lowest for the VCEQ treatment $(F=13.08 ; \mathrm{df}=3,28 ; P<0.0001$; Table 1$)$.

Both plant discovery time and pollinator visit length were significantly different among the treatments (Table 2). Plant discovery time by pollinators was significantly lower
$(F=14.72 ; \mathrm{df}=3,28 ; P<0.0001)$ while pollinator visit length $(F=14.72 ; \mathrm{df}=3,28 ; P<0.0012)$ was found to be significantly higher for VC compared to all other treatments (Table 2). Number of pollinator visits to each of the treatments did not differ significantly, although there was a tendency for the VC plants to have a greater number of visitors compared to all other treatments (Table 2). Similar to the 2009 season there was also a significant $(F=15.56 ; P=$ 0.0016 ) increase in the mean number of native non-bumblebee pollinator visits to VC compared to all other treatments (Table 2). Again, the predominant pollinator species visiting the flowers were bumblebees (Table 2). Unlike the previous field seasons, honeybees were the second predominant pollinators (Table 2). Non-bumblebee native pollinator responses were negligible for NF, CF, and VCEQ, but interestingly, they comprised a significant portion of responders to the VC treatments (Table 2).

3.4. Laboratory Bumblebee (B. impatiens) Microcolony Feeding Experiments. Trial and its interaction with treatment were not found significant for any of the variables tested. Also, VC versus CF treatments did not significantly affect the weight difference (though there was a tendency for VC bees to be heavier) or survival of bees in queenless microcolonies (Table 3$)$. However, ovary length $(F=4.9$; $\mathrm{df}=$ $1,16 ; P=0.0417)$, (Table 3$)$, number of oocytes $(F=$ 22.6; df $=1,16 ; P=0.0002$; Figure 2(A)), and oocyte length $(F=16.6$; df $=1,16 ; P=0.0009)$, (Figure $2(\mathrm{~B}))$ were all found to be significantly increased in bees fed flowers from VC plants. It should also be noted that more bees in the CF-fed cages $(2.1 \pm 0.26)$ displayed lower levels of ovary activation than in the VC-fed cages $(1.3 \pm 0.23)$ 
suggesting that the bees in the CF cages were in the early stages of establishing reproductive dominance hierarchies, and a clear alpha dominant reproductive worker (which suppresses ovary activation in subordinate workers) had not yet emerged.

3.5. Nectar and Pollen Analyses. There were no significant differences in corolla diameter or nectar and pollen weights between the CF and VC flowers used in this assay (data not shown). However, protein content was significantly higher in VC pollen fractions versus CF $(34.5 \pm 2.24$ versus $26.1 \pm$ $1.23 \mathrm{mg} / \mathrm{g}$ dry mass, respectively, $t=3.22 ; P=0.0062$ ). Sugar content was slightly higher in the nectar of VC flowers versus $\mathrm{CF}$, though this was not significant $(96.9 \pm 10.13$ and $98.5 \pm 9.10 \mathrm{mg} / \mathrm{mL})$.

\section{Discussion}

Previous studies have found that soil enhanced with VC amendment can affect plant-pest interactions [18-21, 30, 31]; however, data presented herein demonstrates for the first time that it can also impact plant interactions with beneficial arthropods. Overall, soil VC amendment caused significant increases the time pollinators spent on flowers (in all three years of the study) and significantly lowered time to plant discovery by pollinators (in two of the three years). Soil VC amendment also increased pollen protein content, which correlated with increased ovary activation in bumblebee workers, a trait dependent on protein nutrition. These results suggest that soil quality improvement, as demonstrated by VC amendment in this study, can positively affect interactions with pollinators and provide a higher quality food source for these insects.

As with previous studies [30-32], we found several aspects of plant phenotype modulated by VC soil conditioning. Number of flowers did not differ statistically between CF and VC in 2008 and 2009 but were significantly lower for VC in 2010. Yet, VC plants had heavier flowers than CF in all three years. Flower weights were also significantly higher for VC plants compared to VCEQ and NF in 2010. Additionally, VC plants flowered significantly earlier than the CF in the two years this trait was examined (though note that the 2009 results were marginally significant, with a $P$ value of 0.050 ).

Amendment of soil with VC also significantly altered pollinator interactions with flowers, though the pollinators visiting plants in our study are similar to those reported for cucumber systems by other authors [33]. Pollinators spent more time on the flowers of VC plants compared to those of CF or VCEQ plants in all three years. Time to plant discovery was significantly shorter for VC compared to CF plants in 2009 and 2010, but this was not significantly different in 2008. Pollinators use a variety of cues to identify highquality flowers, primarily visual but also olfactory [25, 33], and this suggests that one or both of these cues may be altered by the soil amendment used in this study. Given that flowers did not differ in size and the number of flowers was in some instances (2010) lower for the VC plants, simple flower-associated visual cues cannot account for the pollinator responses observed. Thus, differences in volatile cues are likely behind the faster plant discovery and enhanced attraction/arrestment observed herein. Buchmann and Cane [34] found that pollinating bees were able to detect pollen level availability in the flowers of Solanum and increase their visitation time and number of sonicating buzzes accordingly. More interestingly, bumblebees collecting pollen from Dodecatheon conjugens and Lupinus sericeus were shown to detect and respond to differences in pollen availability, even though the plant species tested concealed pollen from view $[34,35]$. This indicates that nonvisual cues can in fact influence the pollinator responses to higher quality flowers. Interestingly, in the 2009 and 2010 field assays there was higher proportion of visitations to flowers of VC plants by non-bumblebee native pollinator species, suggesting that the cues produced by these plants are more appealing to these pollinator types.

Our studies also demonstrated that plants grown with VC produce more nutritious floral rewards for pollinators. We found that bumblebee workers that fed on VC-flowers had larger and more developed oocytes than bees fed on CFflowers. Because bumblebee worker reproduction is dependent on dietary protein content $[26,27]$, these results suggest that the nutritional quality of the floral resources produced by the VC-treated plants are higher and thus allowed for more rapid and complete ovary activation in the queenless bumblebee workers. Indeed, chemical analyses demonstrated that protein content of the pollen fractions was significantly higher in VC versus CF plants. It is also worth noting that overall difference in sugar content was an average of $1.6 \mathrm{mg} / \mathrm{mL}$ higher in VC plants, and, although statistically insignificant, such an amount of sugar may still be biologically relevant for pollinators.

Previously published research on soil fertilization on plant-pollinator interactions has yielded variable outcomes. For example, soil phosphorus was shown to influence the size of a pollen grain and its chemical composition, which enhanced pollinator-dependent male flower reproductive success [14]. Baude et al. [36] investigated the effect of N provision through soil litter amendment on plant performance and pollinator resources (nectar sugar) and found disparate, plant-species-dependent responses to the treatments. In other studies, Burkle and Irwin [13, 17, 37] evaluated the impacts of $\mathrm{N}$ fertilization on plant-pollinator interactions in a subalpine natural ecosystem, and found no effects of $\mathrm{N}$ enrichment on the diversity or visitation rate per flower by pollinators, even though floral biomass and seed production responded positively to $\mathrm{N}$ supplementation. Hoover et al. [38] reported that when soil was amended with a simple nitrogen fertilizer, pollinators were not significantly more attracted to the nitrogen treated plants, and, interestingly, bees fed nectar from nitrogen-treated plants had higher mortality. Results from our studies provide further evidence that the effects of VC soil amendment on plant flower traits and pollinator interactions are not simply due to changes in nutrient (N, P, K) availability. In the 2010 studies, VC plants had significantly heavier flowers, had longer pollinator visits, and, though not significant, tended to attract more pollinators than plants grown in soil with VCEQ nutrient levels. Therefore, non-nutritional factors associated with VC amendment, such as microbial interactions, physical 
properties, or non-nutrient chemical compounds, may be responsible for enhancing floral resources. Further studies examining the biotic and abiotic factors associated with VC amendment are necessarily to further understand this system.

Our studies indicate that, in addition to previous documented benefits of VC soil amendment on plant growth, productivity and resistance to diseases and pests [18-21, 39, 40 ], these treatments also enhance plant pollinator attraction and visit length and result in better quality food sources for pollinators. We chose a native bumblebee species to use as a model system for this project due to their small colony size and their predominance as pollinators of cucumber plants. However, we feel certain that the methodology and results obtained are transferable to other pollinator species, as is evident in the responses of non-bumblebee native fauna recorded in this study. These results yield critical information on how soil organic amendments influence aboveground plant symbiotic interactions, and how these could be manipulated to increase ecological services (i.e., pollination) for crop production. Nonetheless, further studies need to be performed to assess field-level applicability of this resource, based on overall arthropod (both pest and beneficial) community responses, cost feasibility, and overall crop performance.

\section{Acknowledgments}

The authors are indebted for the expert comments provided by anonymous reviewers. The authors thank Seth Fornea (USDA-ARS, Raleigh, NC) for facilitating nectar sugar analyses, and Mike Maher, Olivia Campbell, and Janet Griffiths (NCSU, Entomology) and Ruth Watkins (NCSU, Food Bioprocessing and Nutrition Sciences) for their technical support. They also appreciate the statistical advice provided by Dr. Consuelo Arellano (NCSU, Statistics Department). This study was funded by an NCARS project (no. NC02199) and Penn State Center for Pollinator Research awards to Y. J. Cardoza.

\section{References}

[1] C. A. Kearns, D. W. Inouye, and N. M. Waser, "Endangered mutualisms: the conservation of plant-pollinator interactions," Annual Review of Ecology and Systematics, vol. 29, pp. 83-112, 1998.

[2] J. Ollerton, R. Winfree, and S. Tarrant, "How many flowering plants are pollinated by animals?" Oikos, vol. 120, no. 3, pp. 321-326, 2011.

[3] A. M. Klein, B. E. Vaissière, J. H. Cane et al., "Importance of pollinators in changing landscapes for world crops," Proceedings of the Royal Society B, vol. 274, no. 1608, pp. 303-313, 2007.

[4] G. Allen-Wardell, P. Bernhardt, R. Bitner et al., "The potential consequences of pollinator declines on the conservation of biodiversity and stability of food crop yields," Conservation Biology, vol. 12, no. 1, pp. 8-17, 1998.

[5] J. C. Biesmeijer, S. P. M. Roberts, M. Reemer et al., "Parallel declines in pollinators and insect-pollinated plants in Britain and the Netherlands," Science, vol. 313, no. 5785, pp. 351-354, 2006.
[6] D. vanEngelsdorp and M. D. Meixner, "A historical review of managed honey bee populations in Europe and the United States and the factors that may affect them," Journal of Invertebrate Pathology, vol. 103, no. 1, pp. S80-S95, 2010.

[7] S. G. Potts, J. C. Biesmeijer, C. Kremen, P. Neumann, O. Schweiger, and W. E. Kunin, "Global pollinator declines: trends, impacts and drivers," Trends in Ecology and Evolution, vol. 25, no. 6, pp. 345-353, 2010.

[8] C. Carvell, D. B. Roy, S. M. Smart, R. F. Pywell, C. D. Preston, and D. Goulson, "Declines in forage availability for bumblebees at a national scale," Biological Conservation, vol. 132, no. 4, pp. 481-489, 2006.

[9] K. W. Dixon, "Pollination and restoration," Science, vol. 325, no. 5940, pp. 571-573, 2009.

[10] R. J. Mitchell, R. E. Irwin, R. J. Flanagan, and J. D. Karron, "Ecology and evolution of plant-pollinator interactions," Annals of Botany, vol. 103, no. 9, pp. 1355-1363, 2009.

[11] R. Defries, J. A. Foley, and G. P. Asner, "Land-use choices: balancing human needs and ecosystem function," Frontiers in Ecology and the Environment, vol. 2, pp. 249-257, 2004.

[12] A. A. Muñoz, C. Celedon-Neghme, L. A. Cavieres, and M. T. K. Arroyo, "Bottom-up effects of nutrient availability on flower production, pollinator visitation, and seed output in a highAndean shrub," Oecologia, vol. 143, no. 1, pp. 126-135, 2005.

[13] L. A. Burkle and R. E. Irwin, "Beyond biomass: measuring the effects of community-level nitrogen enrichment on floral traits, pollinator visitation and plant reproduction," Journal of Ecology, vol. 98, no. 3, pp. 705-717, 2010.

[14] T.-C. Lau and A. G. Stephenson, "Effects of soil phosphorus on pollen production, pollen size, pollen phosphorus content, and the ability to sire seeds in Cucurbita pepo (Cucurbitaceae)," Sexual Plant Reproduction, vol. 7, no. 4, pp. 215-220, 1994.

[15] D. R. Campbell and K. J. Halama, "Resource and pollen limitations to lifetime seed production in a natural plant population," Ecology, vol. 74, no. 4, pp. 1043-1051, 1993.

[16] M. C. Gardener and M. P. Gillman, "The effects of soil fertilizer on amino acids in the floral nectar of corncockle, Agrostemma githago (Caryophyllaceae)," Oikos, vol. 92, no. 1, pp. 101-106, 2001.

[17] L. A. Burkle and R. E. Irwin, "The effects of nutrient addition on floral characters and pollination in two subalpine plants, Ipomopsis aggregata and Linum lewisii," Plant Ecology, vol. 203, no. 1, pp. 83-98, 2009.

[18] Y. J. Cardoza, "Arabidopsis thaliana resistance to insects, mediated by an earthworm-produced organic soil amendment," Pest Management Science, vol. 67, no. 2, pp. 233-238, 2011.

[19] A. G. Little, C. Arellano, G. G. Kennedy, and Y. J. Cardoza, "Bottom-up effects mediated by an organic soil amendment on the cabbage aphid pests Myzus persicae and Brevicoryne brassicae," Entomologia Experimentalis et Applicata, vol. 139, no. 2, pp. 111-119, 2011.

[20] A. G. Little and Y. J. Cardoza, "Host plant effects on generalist and specialist lepidopterous cabbage pests modulated by organic soil amendment," Pedobiologia, vol. 54, no. 5-6, pp. 353-359, 2011.

[21] N. Q. Arancon, P. A. Galvis, and C. A. Edwards, "Suppression of insect pest populations and damage to plants by vermicomposts," Bioresource Technology, vol. 96, no. 10, pp. 1137-1142, 2005.

[22] T. T. Makino, K. Ohashi, and S. Sakai, "How do floral display size and the density of surrounding flowers influence the likelihood of bumble bee revisitation to a plant?" Functional Ecology, vol. 21, no. 1, pp. 87-95, 2007. 
[23] G. Bloch, "Regulation of queen-worker conflict in bumble-bee (Bombus terrestris) colonies," Proceedings of the Royal Society B, vol. 266, no. 1437, pp. 2465-2469, 1999.

[24] G. Bloch and A. Hefetz, "Regulation of reproduction by dominant workers in bumblebee (Bombus terrestris) queenright colonies," Behavioral Ecology and Sociobiology, vol. 45, no. 2, pp. 125-135, 1999.

[25] D. Goulson, Bumblebees: Their Behaviour and Ecology, Oxford University Press, Oxford, UK, 2003.

[26] A. Génissel, P. Aupinel, C. Bressac, J.-N. Tasei, and C. Chevrier, "Influence of pollen origin on performance of Bombus terrestris micro-colonies," Entomologia Experimentalis et Applicata, vol. 104, no. 2-3, pp. 329-336, 2002.

[27] J. N. Tasei and P. Aupinel, "Validation of a method using queenless Bombus terrestris micro-colonies for testing the nutritive value of commercial pollen mixes by comparison with queenright colonies," Journal of Economic Entomology, vol. 101, no. 6, pp. 1737-1742, 2008.

[28] A. Farkas and E. Zajac, "Nectar production for the Hungarian honey industry," European Journal of Plant Science and Biotechnology, vol. 1, no. 2, pp. 125-151, 2007.

[29] SAS Institute, SAS/STAT User's Guide for SAS, SAS Institute, Cary, NC, USA, 2006.

[30] N. Q. Arancon, C. A. Edwards, P. Bierman, C. Welch, and J. D. Metzger, "Influences of vermicomposts on field strawberries: 1. Effects on growth and yields," Bioresource Technology, vol. 93, no. 2, pp. 145-153, 2004.

[31] N. Q. Arancon, C. A. Edwards, E. N. Yardim, T. J. Oliver, R. J. Byrne, and G. Keeney, "Suppression of two-spotted spider mite (Tetranychus urticae), mealy bug (Pseudococcus $s p$ ) and aphid (Myzus persicae) populations and damage by vermicomposts," Crop Protection, vol. 26, no. 1, pp. 29-39, 2007.

[32] R. M. Atiyeh, N. Q. Arancon, C. A. Edwards, and J. D. Metzger, "The influence of earthworm-processed pig manure on the growth and productivity of marigolds," Bioresource Techno$\log y$, vol. 81, no. 2, pp. 103-108, 2002.

[33] N. A. Barber, L. S. Adler, and H. L. Bernardo, "Effects of above- and belowground herbivory on growth, pollination, and reproduction in cucumber," Oecologia, vol. 165, no. 2, pp. 377-386, 2011.

[34] S. L. Buchmann and J. H. Cane, "Bees assess pollen returns while sonicating Solanum flowers," Oecologia, vol. 81, no. 3, pp. 289-294, 1989.

[35] D. F. Gori, "Floral color change in Lupinus argenteus (Fabaceae)—why should plants advertise the location of unrewarding flowers to pollinators?" Evolution, vol. 43, no. 4, pp. 870-881, 1989.

[36] M. Baude, J. Leloup, S. Suchail et al., "Litter inputs and plant interactions affect nectar sugar content," Journal of Ecology, vol. 99, no. 3, pp. 828-837, 2011.

[37] L. Burkle and R. Irwin, "The importance of interannual variation and bottom-up nitrogen enrichment for plant-pollinator networks," Oikos, vol. 118, no. 12, pp. 1816-1829, 2009.

[38] S. E. R. Hoover, J. J. Ladley, A. A. Shchepetkina, M. Tisch, S. P. Gieseg, and J. M. Tylianakis, "Warming, $\mathrm{CO}_{2}$, and nitrogen deposition interactively affect a plant-pollinator mutualism," Ecology Letters, vol. 15, no. 3, pp. 227-234, 2012.

[39] N. Q. Arancon, C. A. Edwards, R. Atiyeh, and J. D. Metzger, "Effects of vermicomposts produced from food waste on the growth and yields of greenhouse peppers," Bioresource Technology, vol. 93, no. 2, pp. 139-144, 2004.

[40] F. A. Gutiérrez-Miceli, J. Santiago-Borraz, J. A. Montes Molina et al., "Vermicompost as a soil supplement to improve growth, yield and fruit quality of tomato (Lycopersicum esculentum)," Bioresource Technology, vol. 98, no. 15, pp. 2781-2786, 2007. 

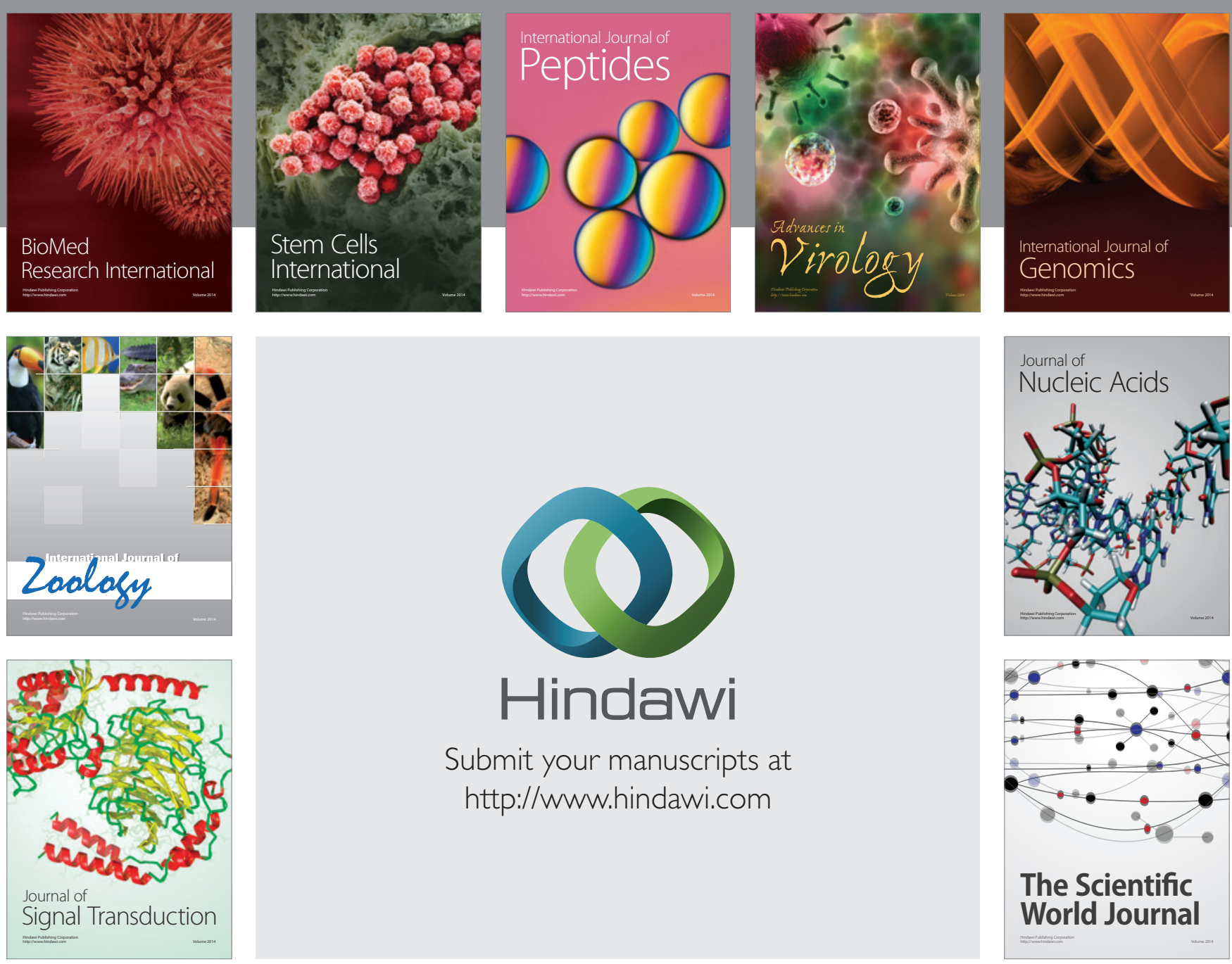

Submit your manuscripts at

http://www.hindawi.com
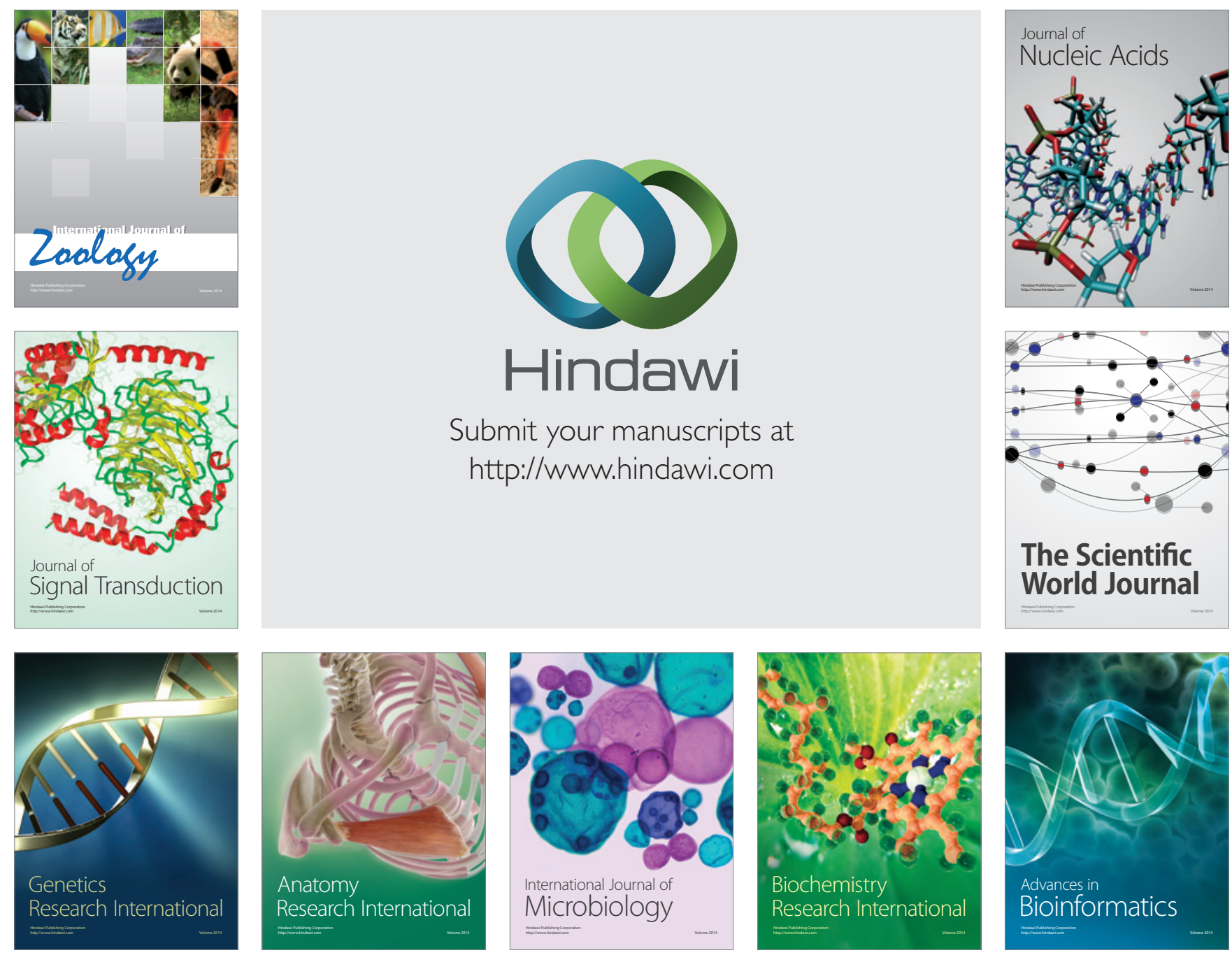

The Scientific World Journal
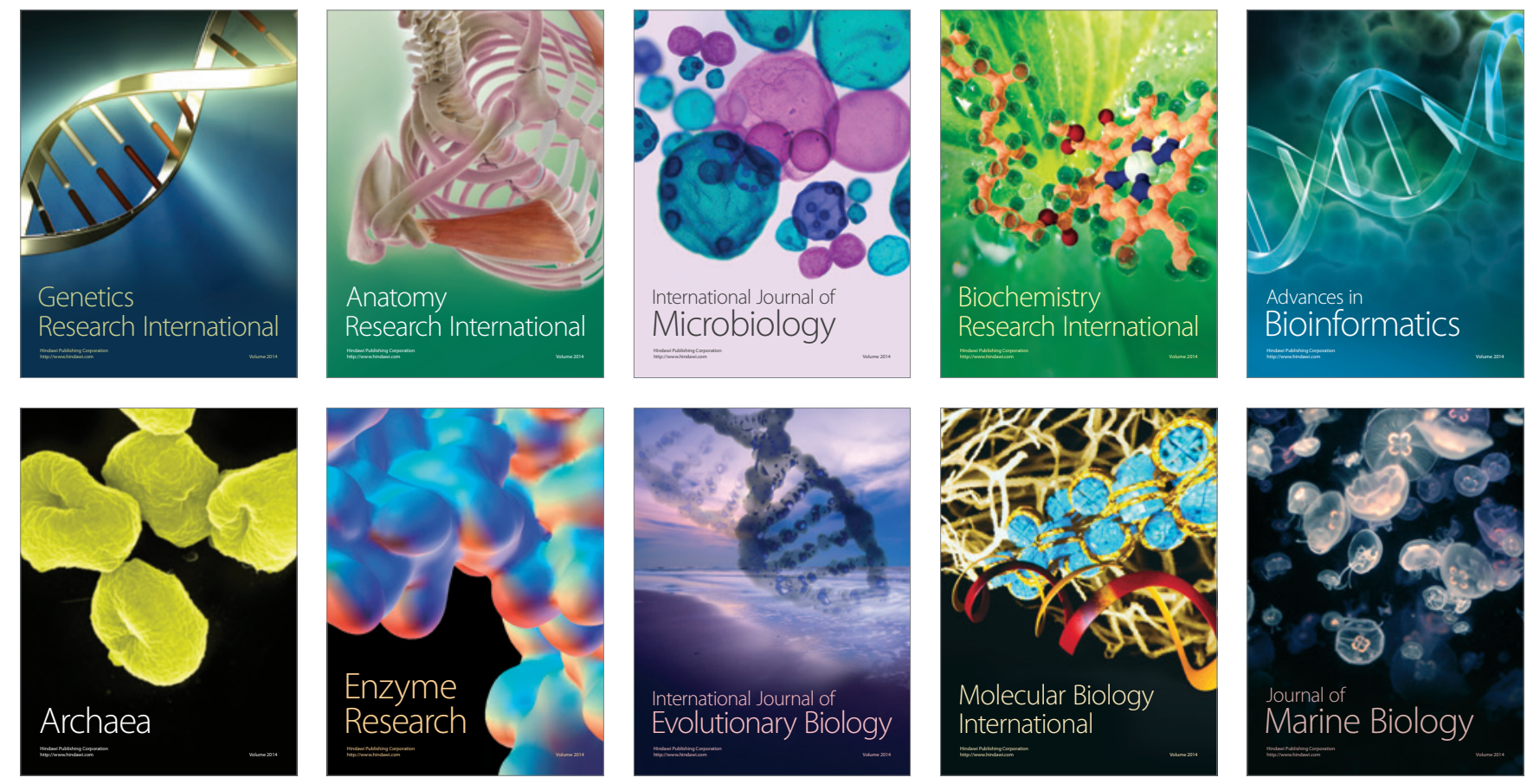